\title{
A variance analysis of the capacity displaced by wind energy in Europe
}

\section{Giebel, Gregor}

Published in:

Wind Energy

Link to article, DOI:

10.1002/we.208

Publication date:

2007

Document Version

Early version, also known as pre-print

Link back to DTU Orbit

\section{Citation (APA):}

Giebel, G. (2007). A variance analysis of the capacity displaced by wind energy in Europe. Wind Energy, 10(1), 69-79. https://doi.org/10.1002/we.208

\section{General rights}

Copyright and moral rights for the publications made accessible in the public portal are retained by the authors and/or other copyright owners and it is a condition of accessing publications that users recognise and abide by the legal requirements associated with these rights.

- Users may download and print one copy of any publication from the public portal for the purpose of private study or research.

- You may not further distribute the material or use it for any profit-making activity or commercial gain

- You may freely distribute the URL identifying the publication in the public portal

If you believe that this document breaches copyright please contact us providing details, and we will remove access to the work immediately and investigate your claim. 


\section{Research Article A Variance Analysis of the Capacity
Displaced by Wind Energy in Europe}

Gregor Giebel*, Ris $\emptyset$ National Laboratory, PO Box 49, DK-4000 Roskilde, Denmark

Key words: large-scale integration; dispersed turbine systems; complementary power plant; fossil fuel power generation

\begin{abstract}
Wind energy generation distributed all over Europe is less variable than generation from a single region. To analyse the benefits of distributed generation, the whole electrical generation system of Europe has been modelled including varying penetrations of wind power. The model is chronologically simulating the scheduling of the European power plants to cover the demand at every hour of the year. The wind power generation was modelled using wind speed measurements from 60 meteorological stations for 1 year. The distributed wind power also displaces fossil-fuelled capacity. However, every assessment of the displaced capacity (or a capacity credit) by means of a chronological model is highly sensitive to single events. Therefore the wind time series was shifted by integer days against the load time series, and the different results were aggregated. The same set of results is shown for two other options, one where the pump storage plants are used more aggressively and the other where all German nuclear plants are shut off. NCEP/NCAR reanalysis data have been used to recreate the same averaged time series from a data set spanning 34 years. Through this it is possible to set the year studied in detail into a longer-term context. The results are that wind energy can contribute more than $20 \%$ of the European demand without significant changes in the system and can replace conventional capacity worth about $10 \%$ of the installed wind power capacity. The long-term reference shows that the analysed year is the worst case for wind power integration. Copyright @ 2006 John Wiley \& Sons, Ltd.
\end{abstract}

Received 29 January 2006; Revised 14 June 2006; Accepted 3 July 2006

\section{Introduction}

The fact that wind energy is not always available from any single cluster of turbines has given rise to criticism of wind power as not being reliable and needing the same amount of additional back-up as the installed wind power. This is obviously wrong, as wind power is these days built additionally to a grid already sufficient to supply the demand on its own. What is right though is that adding $1 \mathrm{MW}$ of wind power does not increase the security of supply in the same way as adding $1 \mathrm{MW}$ of conventional generation (e.g. gas-fired). As the supply of conventional fuels is usually not a problem, the only insecurity associated with conventional generation is the technical availability, which for most modern power plants is in the high $90 \%$ range. While wind turbines reach technical availabilities of over $98 \%$, they are dependent on the fuel, i.e. wind, which is variable. For low wind speeds and very high wind speeds the turbine does not produce electricity. On the other hand, both calms and storms are local events, and sufficiently spread-out wind power generation is much less variable and more secure than wind power from a single location or region. The increase in secured capacity to supply the electrical load is called a capacity credit. It is usually expressed as a percentage of the installed

\footnotetext{
* Correspondence to: G. Giebel, Ris $\varnothing$ National Laboratory, PO Box 49, DK-4000 Roskilde, Denmark

E-mail: gregor.giebel@ risoe.dk

Contract/grant sponsor: Marie Curie Fellowship; contract/grant number: JOR3-CT97-5004
} 
wind power capacity. Though many studies have been performed on the capacity credit of wind energy in single countries, none so far has looked at the benefits of distributing the generation all over Europe.

The capacity credit concept is most relevant for the discussion in the classical, vertically integrated utility world, where everything related to electricity was in one hand and the generation system, transmission system and distribution network could be planned with long lead times. This explains the lack of attention the topic has received in recent years. Since the liberalization of the markets and the unbundling of the Transmission System Operator (TSO) responsible for the stability of the system from the (many) power generation companies, the situation has become more complex. The idea behind the liberalized market is to force competition in the electricity system, thereby reducing prices for the consumer, while letting the TSO handle the stability of the grid. In this system the market rules are more important than in the old set-up, and overly zealous market rules can work against system stability. For example, in Europe the market price for electricity is artificially low owing to the still existing overcapacity of written-off power plants, which makes it not economic to invest in new power plants, except for incumbent large power companies that can take a similar capacity out of the market. Having said all this, the capacity credit still goes into the long-term adequacy considerations for the power system, be it market-based or liberalized.

This article presents the main results of a study on the benefits of distributing wind power all over Europe, also available as a full thesis text. ${ }^{1}$ For a compendium of existing studies on the capacity credit of wind energy, see Reference 2. The common feature of all the studies quoted there is that for small penetrations the capacity credit of wind energy is close to the average load factor, while for high penetrations it approaches a value mainly determined by the minimum load factor. However, as Milligan ${ }^{3}$ pointed out, the assessment of a capacity credit by means of a chronological model like the one used in this article is highly sensitive to single events. Therefore a variational analysis is carried out, shifting the wind power profile by 50 days in both directions against the load time series. Using this technique, it was possible to determine the influence of the power plant mix and the scheduling strategy on the capacity credit. The sensitivity is high not only for single events and their distribution during the year but also for the variation of wind power from year to year. Therefore, if only 1 year of data is available, as in the article at hand, reanalysis data can be used to put the assessment into context.

\section{Models, Methods and Data}

\section{National Grid Model}

The assessment of the economic value of wind energy and wind power forecasting is done using the National Grid Model (NGM) of Rutherford Appleton Laboratory, UK. ${ }^{4,5}$ Detailed information is needed on the power plants available for dispatch and on the prices for fossil fuel. Additionally, three time series are needed: electricity demand on the whole grid, wind power measurements and possibly wind power forecasts (persistence and perfect forecasting are calculated within the program itself).

The NGM models the scheduling and dispatch of power plant to meet the demand on a large-scale electricity grid. As such, it is a one-node model, where transmission losses or bottlenecks are not an issue. However, for most of Europe, where nearly all countries are part of UCTE, this is not far from the truth for moderate penetrations. Nonetheless, the losses involved in wheeling large-scale power physically from Spain to Sweden would be prohibitively large.

In this set-up the model runs in hourly time steps. At every step the number of power plants needed in the next hours to cover the predicted demand is scheduled ahead. All power plants are listed in merit order, so the operators first choose the plant with the lowest production cost per $\mathrm{kWh}$ and then work their way through the list up to the number of plants needed to cover the predicted demand. At this stage the predicted wind power is treated as negative load. Therefore wind power replaces the least efficient and probably also most polluting power plants first. To account for the uncertainty of the demand, the predicted demand is calculated by multiplying the actual demand by a Gaussian-distributed random number with a distribution mean of 1 and a standard deviation of 0.015. This uncertainty is consistent with published deviations for load prediction algorithms 
Table I. Details of the power stations used in the NGM: OCGT, open cycle gas turbine; CCGT, combined cycle gas turbine; CR\&W, combustible renewables and waste. The pump storage efficiency is one-way

\begin{tabular}{lccc}
\hline Type & Start-up time $(\mathrm{h})$ & Cost $(€ \mathrm{c} / \mathrm{kWh})$ & Mean efficiency \\
\hline Nuclear & NA & NA & $0 \cdot 70^{\mathrm{b}}$ \\
Coal & 8 & 0.7294 & $0 \cdot 35814$ \\
Oil & 8 & 0.9489 & $0 \cdot 35755$ \\
OCGT & 0 & $8 \cdot 6245^{\mathrm{a}}$ & $0 \cdot 1987$ \\
CCGT & 1 & $1 \cdot 0204$ & $0 \cdot 54685$ \\
CR\&W & 8 & 0.8793 & $0 \cdot 305$ \\
Hydro & NA & NA & NA \\
Pump storage & NA & NA & 0.88475 \\
\hline
\end{tabular}

NA, not applicable.

${ }^{\mathrm{a}}$ The cost for OCGT is $€^{*} \mathrm{c} / \mathrm{kWh}_{\mathrm{el}}$. All other costs are fuel prices in $€ \mathrm{c} / \mathrm{kWh}_{\mathrm{th}}$.

${ }^{\mathrm{b}}$ Average lifetime load factor.

(see e.g. References 6-8). The eight plant types treated in this model can be found in Table I, together with the associated prices for fuel.

An assumption is made for each type of plant regarding its start-up time: a maximum of $8 \mathrm{~h}$ is assigned to coal- and oil-fired plant, while OCGTs are considered to start up immediately within the hourly time step of the model. Obviously, the fraction of OCGTs in the modelled grid strongly influences the overall response time of the grid. The $8 \mathrm{~h}$ maximum also limits the time frame for looking ahead: there is no need to look beyond the maximum start-up time. Nuclear plant is treated as always running with an output determined by the rated capacity times the lifetime load factor. During 6 weeks in summer the nuclear production is scaled back to $70 \%$ owing to scheduled maintenance and fuel rod changes. Hydro plant is predominantly (90\%) used as base plant with a generation according to season: in late winter the generation is higher than in late summer. Hydro power dams are not modelled explicitly. The possibility to use less of the available water to smooth out some of the fossil or nuclear generation is therefore solely the responsibility of the pumped hydro storage plants. Thermal power plants cannot be operated at less than $50 \%$ load factor.

Any shortfalls in load not covered by the scheduled power plant are met either by fast response plant (pumped hydro or gas turbines) or through the spinning reserve. This is thermal plant that is not being run at full output but at, say, 95\%. The remaining 5\% can be activated very fast if need be. The spinning reserve is planned as a fraction of the predicted load (SR1) as well as a fraction of currently available wind power (SR2). Both these fractions remain fixed for a model run (typically 1 year) but are optimized across model runs to yield minimum fossil fuel cost under the condition that no loss-of-load events (LOLE) occur. Since power plants can only be dropped from service from one time step to the next in the model, not all of the wind power production can be accepted into the grid when all running steam plants are already at the minimum load or when the demand is already covered by the sum of nuclear and hydro power and a fraction of the available wind power. The rest of the generated wind power is then discarded. Note that, in a country with hydro dams, most of the wind power would be used instead of stored water. Since this is not modelled, the amount of discarded wind power is probably lower in reality than in the model results.

This model set-up is then run for added capacities of $0 \%, 1 \%, 2 \%, 3 \%, 5 \%, 10 \%, 20 \%, 30 \%, \ldots, 100 \%$ of wind energy as a percentage of the existing plant mix. This percentage refers to added nameplate windgenerating capacity in relation to the existing conventional power plant capacity. First, SR1 is optimized at zero wind energy. Then, at higher additional wind energy, SR1 is kept stable and SR2 is optimized.

Another possibility is to optimize for lowest fossil fuel cost at every step, yielding the best combination of SR1, SR2 and an additional parameter detailing how aggressively to use pump storage plant for peak lopping. Peak lopping is the smoothing out of the load curve using a smaller or higher amount of the available pump storage plant for scheduled generation. Since the model optimizes for minimum fossil fuel cost, pump storage 
is essentially deemed free to use, but it increases the amount of fossil fuel used multiplied by its efficiency percentage. This approach was used for the graphs denoted 'peak lopping'.

To assess the influence of wind power forecasting, two different forecasting methods are used. One is perfect forecasting and uses the time series itself as a forecast. The inclusion of this model yields an upper boundary for the usefulness of wind energy forecasting as well as for wind power in general. The other model is persistence, which is quite reasonable, since the maximum forecast horizon needed is $8 \mathrm{~h}$. This model sets the lower bound of what is possible with short-term forecasting. Actually, forecasts on the basis of numerical weather prediction models (NWPs) alone might fare even worse, since these have significant error for the $0 \mathrm{~h}$ forecast and only get better than persistence after about $4 \mathrm{~h} .{ }^{9}$ Nevertheless, in a real-world application it would be very unwise not to use online measurement data and hence get the $0 \mathrm{~h}$ prediction error down.

\section{European Wind Data}

The European wind data came from 60 meteorological stations in the selected countries and are detailed elsewhere. ${ }^{1,10,11}$ The geographical distribution can be found in Figure 1. The data extended from December 1990 to December 1991 inclusive.

The wind was scaled to a height of $50 \mathrm{~m}$ above ground level (a.g.l.) using the sector-dependent roughnesses from the WAsP analyses published in Reference 11 in the logarithmic wind profile. In order to calculate the total European wind power generation from these sites, a European average wind turbine distribution ${ }^{12}$ was used corresponding to a $6 \cdot 1 \mathrm{MW}$ unit. The distribution was representative for early 2000 , thereby excluding the largest new machines now on the market. However, a similar analysis with different power curves and for $80 \mathrm{~m}$ height a.g.l. has shown that the main findings of this study are unaffected. ${ }^{13}$

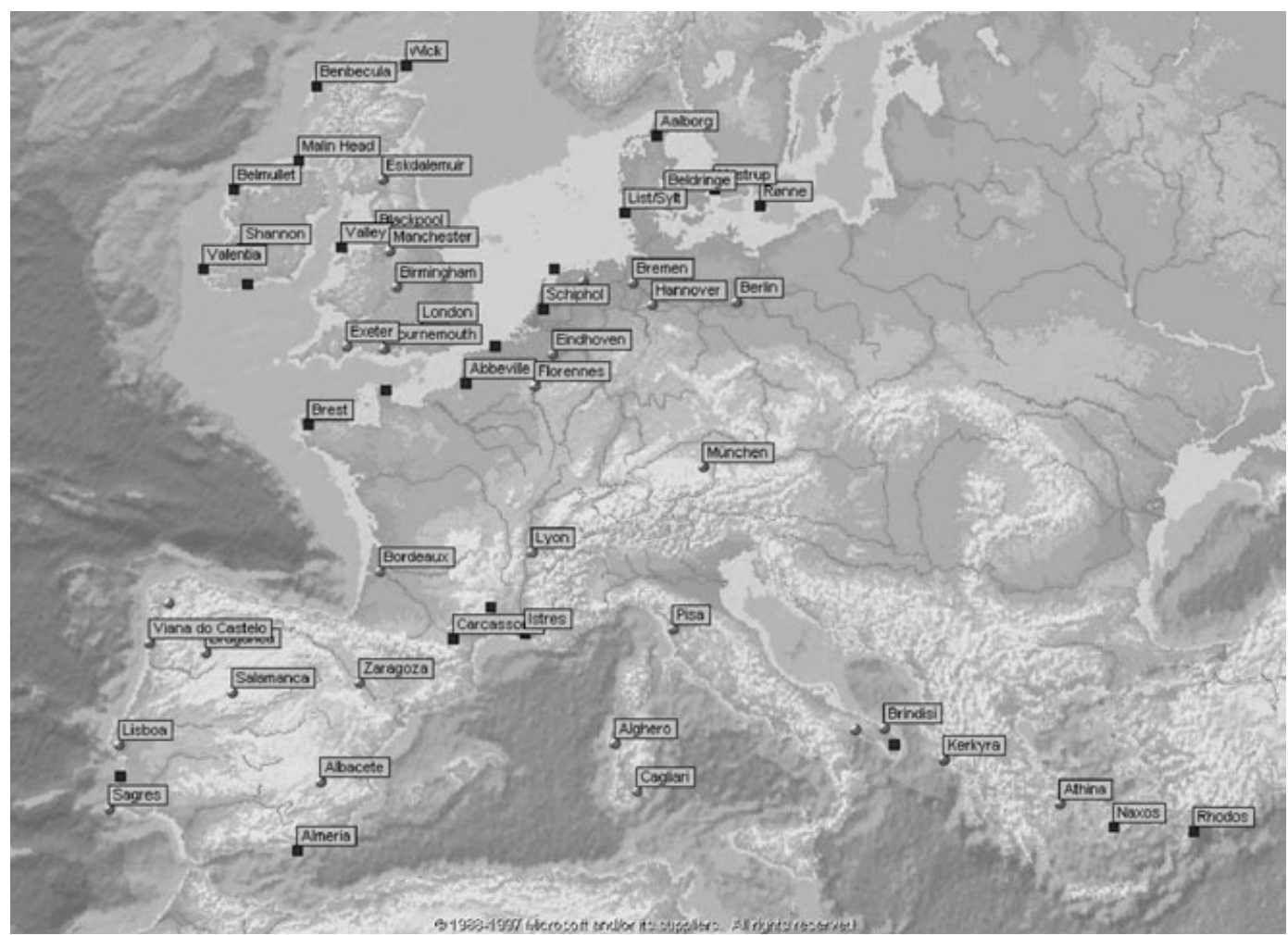

Figure 1. The meteorological sites used. The squares are stations of over 2000 full load hours. If the name is missing, it means that too many data were missing to use the station on its own 
Using the superposed power curve for each site, the power output time series was aggregated over Europe for each hour. This time series is referred to as 'average'. In order to measure the effects of a time series with higher load factor but also higher variability, the single-site time series with the highest production was used. This came from Malin Head in Ireland, yielding 3865 full load hours (FLH, defined as the yearly production in MWh divided by the number of MW installed).

\section{European Grid Data}

The installed capacity in the selected countries (AT, BE, CH, DE, DK, ES, FR, GR, IE, IT, NL, PT and UK) was available, ${ }^{14}$ broken down by plant type. Additionally, the full individual power unit details for England/Wales, Ireland and Portugal were known, as were the details of all European nuclear power stations. ${ }^{15}$ To assess the influence of the decision of the German government to shut down all nuclear power stations $(\sim 17.5 \mathrm{GW})$, in one run they have been taken out of the power plant mix without replacement. The corresponding graphs are denoted 'no DE nukes'. For each plant category the known size distributions of the available countries were scaled up to the appropriate total capacity. The overall capacity for all categories is $461.42 \mathrm{GW} .{ }^{14}$ However, the available capacity on the day of the highest demand was only $321.13 \mathrm{GW}$. Since the NGM does not take scheduled or forced outages into account, this installed capacity was chosen for the modelling of the whole power plant mix.

The demand time series were available from France (EDF), England/Wales (CEGB) and Portugal (EdP). These were scaled in order to fit the overall European load, which was $1603 \mathrm{TWh}$.

The wind and load time series were from 1991, since the effect of the wind on the demand was deemed important too. However, the aggregated numbers of total demand and installed capacity were scaled to the values for 2000 .

\section{European Wind Data from Reanalysis}

The reanalysis project ${ }^{16}$ is an effort to reanalyse historical meteorological data with a state-of-the-art weather model. The aim here is to create one consistent data set without artificial trends that were introduced at a model change. One can think of it as a meteorologically sound way to extrapolate between measurements.

The data were from 1965-1998 and comprised 12-hourly 10 min averages of wind speed at $10 \mathrm{~m}$ height a.g.l. The time series were from the grid points nearest to the meteorological stations used above. Since the mean of these time series was slightly different from the mean of the meteorological data series, the reanalysis wind speed was normalized to yield the same mean wind speed as the meteorological data for the period from December 1990 to December 1991. The wind time series was converted to a power output by the same method as the measured wind speeds of 'European Wind Data'.

\section{Capacity Effects}

\section{Benefits of Distributed Production}

The properties of the different time series are shown below. While the time series with the highest generation has nearly 4000FLH, the lowest wind speeds are found in Munich, corresponding to 853 FLH. This is an example of a site that would not see wind power development unless the local topography significantly enhanced the resource (as in Munich, where the only wind turbine within city boundaries is built on a $\sim 100 \mathrm{~m}$ high garbage mound). Also, taking these marginal sites into account leads to more measuring points being available from the data set. In Reference 1, results are also shown using a data set with a cut-off below $2000 \mathrm{FLH}$, leaving 25 sites. However, since the results are not very dissimilar to the ones using the 'average' series, those results have been left out of this article for clarity of presentation.

The amount of smoothing of the time series achieved by averaging the generation over a large area can be seen from Table II. While the single highest time series from Malin Head reaches both zero and maximum 
Table II. Properties of the European time series: $\sigma$ is the standard deviation of the resulting time series, $\sigma_{\text {rel }}$ is the standard deviation divided by the mean, FLH is the full load hours and LF is the load factor. Mean, $\min , \max$ and $\sigma$ are in $\mathrm{kW}$ relative to the 6.1 MW unit explained in 'European Wind Data'

\begin{tabular}{lrrrrrrr}
\hline Time series & Mean & Min & Max & $\sigma$ & $\sigma_{\text {rel }}(\%)$ & FLH (h) & LF (\%) \\
\hline Average & 1347 & 94 & 4085 & 773 & 0.57 & 1934 & $22 \cdot 1$ \\
Malin Head & 2646 & 0 & 6096 & 2202 & 0.83 & 3800 & $43 \cdot 4$ \\
\hline
\end{tabular}

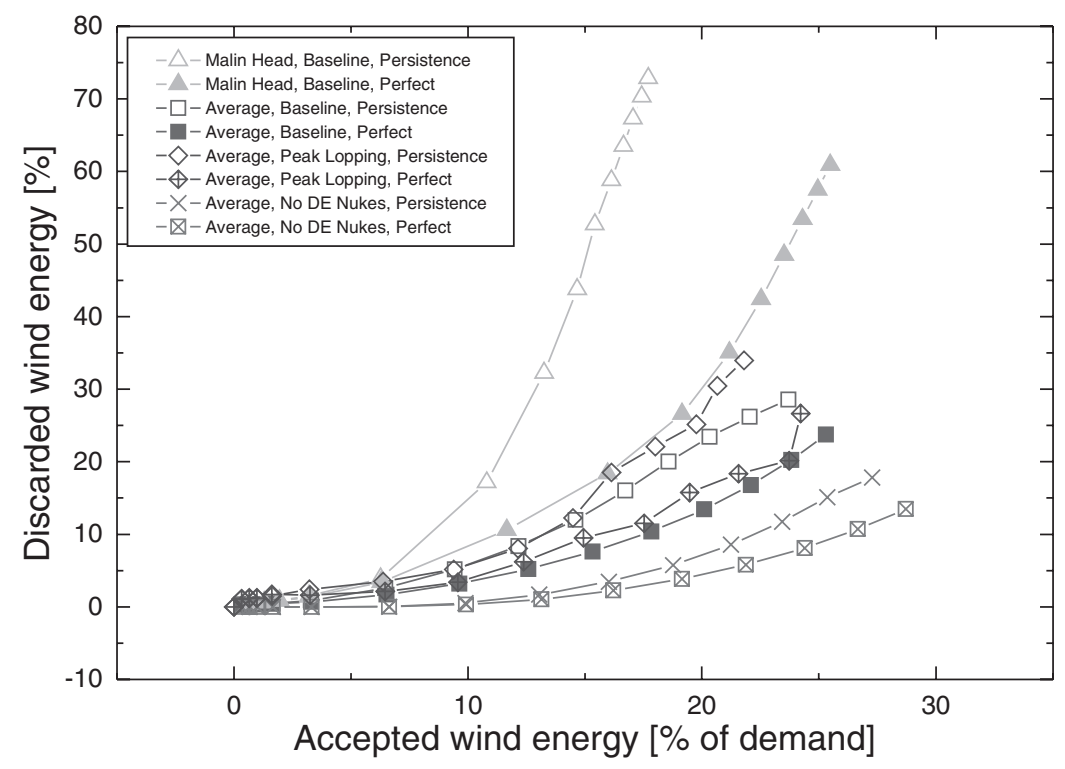

Figure 2. Discarded wind energy production. The figure shows the percentage of generated wind energy that is not accepted into the grid as a function of the percentage of demand covered by wind energy. 'Persistence' (open symbols) and 'perfect' are the two forecasting options described in the text

generation, the 'average' series has a minimum generation that is not null $(\sim 1.5 \%)$, and stays at all times well below the installed capacity (with a maximum at 67\%). This is even more pronounced for the gradients: there is a $37 \%$ probability that the next hour's output of the European average will be within $1.6 \%$ of its value now, while there is a $1.6 \%$ (cumulative) probability that the output from Malin Head will decrease by $20 \%$ or more. This effect comes from the weaker correlation of time series from distant places. While the cross-correlation of wind power time series varies widely even for the same distance, a fit through the cloud of points finds an exponential decay on a scale of about $725 \mathrm{~km}$. The correlation is completely random for distances over $\sim 3000 \mathrm{~km}$.

Since the grid (model) can only accept wind energy as a replacement for fossil fuel, wind energy has to be discarded when the demand is already covered by the base load generation (nuclear and hydro) and some fraction of the wind energy, or when all fossil plants are already at a minimum. Figure 2 shows the amount of wind energy that has to be discarded as a function of the (demand) penetration of wind energy in the grid. For small penetrations, nearly no wind energy has to be discarded, while at higher penetrations the percentage of discarded wind energy rises strongly. While the graph looks complex at first, it is built up of two different wind time series (Malin Head and the 'average' series), including two additional options for the 'average' time series: 'no DE nukes' and the more aggressive 'peak lopping'. These four options come in two forecasting flavours, 'perfect' and 'persistence' (open symbols). The graph shows that wind energy can be integrated to about $15 \%$ 
of covered demand with just $10 \%$ of wind energy wasted owing to the assumptions built into the model (the line denoted 'average, baseline, persistence'). This is only valid for the smooth averaged time series, since Malin Head already wastes $10 \%$ at about $10 \%$ of demand covered. For perfect forecasting, the result becomes even better: nearly $20 \%$ of the total electricity demand can be covered before $10 \%$ of the wind power production has to be dumped (the full squares of 'average, baseline, perfect'). Using perfect forecasting for Malin Head, the result is $12.5 \%$.

Comparing the two forecasting options in the baseline cases shows that the higher the variability in the wind power, the higher is the value of accurate forecasting even for small penetrations. Aggregating the output helps twofold here: the aggregated time series is less variable in itself and thereby easier to forecast, and the forecasting errors are only weakly correlated throughout a region, ${ }^{17}$ thereby reducing the forecasting error of a region in comparison with that of a single wind farm. Using an aggressive peak-lopping strategy does not change the result much (in part because the daily peak/trough of the European load time series is not so pronounced as in a single, national load time series).

Interesting here is the result for a more flexible power plant mix with less base load generation: in the case of the shutdown of all German nuclear plants, much more fossil fuel has to be burnt to make up for the lost nuclear generation. Since this replacement is modelled as being easily controllable, a more flexible plant mix emerges, giving rise to a higher amount of wind energy that can be accepted into the grid. Therefore much less wind energy has to be discarded, giving a higher percentage of demand covered at the same penetration.

Discarding $10 \%$ of the generated wind energy may sound like a lot, but it is not, owing to the assumptions made in the NGM. In the model, hydro power is pure base load and (except for the pump storage plants) cannot be used for system stability purposes. This is equivalent to saying that all the hydro power in the model is of the run-of-river type. In reality, reservoir-fed hydro power will take most of the energy provided. Of the $\sim 100$ $\mathrm{GW}$ of hydro power generation installed in Europe, about half is connected to some kind of reservoir, although the reservoirs are concentrated in mountainous terrain, e.g. the Alps or Norway. At the very least the reservoirs are capable of holding back some generation for a few hours, though typically the time scale should be weeks. Therefore most of the energy here would not be produced at once by hydro power but deferred for later use.

In the European grid analysed here, the total cost of fossil fuel for 1 year without any wind energy is 11.63 $\mathrm{G€}$. For the peak-lopping strategy it is $11.06 \mathrm{G} €$, while without the German nuclear plants the fossil fuel cost is $14.25 \mathrm{G} €$. Keep in mind that pollutant and $\mathrm{CO}_{2}$ emissions rise and fall in the same order of magnitude. In Figure 3 we see that the possible fossil fuel savings correlate with the amount of wind energy fed into the network (i.e. the gross wind energy production minus the discarded wind energy from Figure 2). Covering $20 \%$ of the total electricity consumption of Europe with wind energy means that close to $60 \%$ of all fossil fuel costs could be saved in the baseline option. This corresponds to about 6-7 G€. The 'no DE nukes' option has higher absolute numbers for the savings but lower relative ones. The difference between baseline and peak lopping is small. All the data points (except the first four, which are closer together) of the different graphs are equidistant in installed wind capacity. The fact that the four lines for the baseline options, Malin Head (twice) and the 'average' time series (also twice), are so close together means that, in the scaling using accepted wind energy as $x$-axis, the main influence is the plant mix, especially the relative amounts of fossil fuel generation in the mix. Keep in mind that most of the variation between the time series is leading to different amounts of discarded wind production. Forecasting can make a difference. The spread between the forecasting methods is larger for more variable wind energy generation (not shown in Figure 3).

\section{Variational Analysis}

Since the NGM does not take forced or scheduled outages into account, a proper capacity credit assessment based on the calculation of loss-of-load probability is not possible with the NGM. However, it is possible to ask the NGM how much fossil fuel capacity was used during the run. The unused fossil fuel capacity (or surplus capacity) is then the capacity used at zero wind power penetration minus the capacity used at higher penetration. 


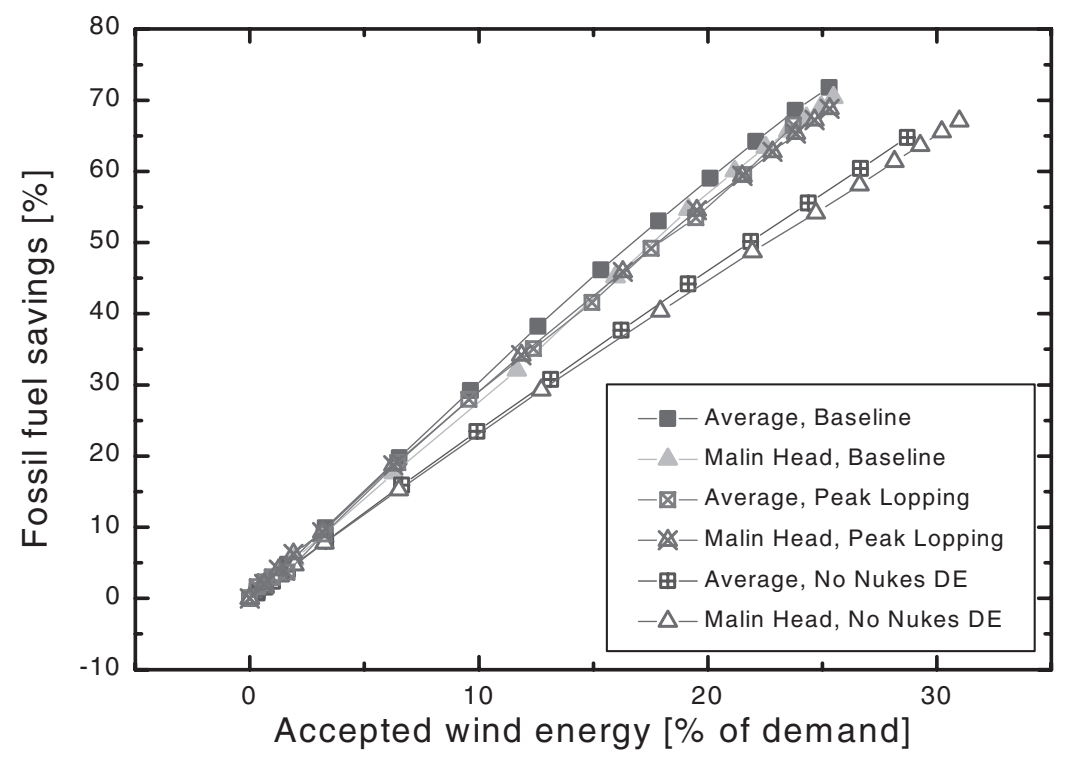

Figure 3. Fossil fuel savings for different wind energy production and different plant mixes. The $x$-axis denotes the percentage of total electricity demand covered by wind energy. Only perfect forecasting is shown

The unused fossil fuel capacity correlates with the load factor at the hour of the highest fossil fuel demand. Note that this does not need to be the highest overall demand, depending on the nuclear and hydro power strategy, although it should be close by. However, considering the variability of wind power between weeks in a year and between years for the same week, the capacity credit of wind energy for small penetrations is more or less randomly distributed in the same way as wind power generation is distributed. The overall highest demand is found in a 7 week period in winter, ranging from the second week in January to the third week in February. The variability of the load over many years is quite small, at least for the northern European countries not seeing the peak generation happen owing to air conditioning in summer, so this 7 week period should be more or less the same over all years, barring extremely cold winter periods outside of these 7 weeks.

To overcome the single-event problem, a variational analysis was done by shifting the wind time series relative to the load time series. Since the load time series exhibits a diurnal variation, it was decided to only shift the series by whole days. This was done here for \pm 50 days, since using even more days the seasonal cycle would have been neglected. Note that the financial benefits from saved fossil fuel (as in Figure 3) are largely unaffected by the shifting, since these depend on the total amount of accepted wind energy.

For Figure 4, all the instances of relative displaced capacity (the unused fossil fuel capacity expressed as a percentage of the installed wind power capacity) have been calculated using the shifting process and perfect forecasting (persistence forecasting hardly changes the result). The average displaced capacity is plotted together with the standard deviation of the instances. For the European 'average' wind analysed here, the unused fossil fuel capacity is about $9 \%$ of the installed wind power capacity at $45 \%$ penetration for all three options. For $20 \%$ demand covered, the capacity credit is around $10 \%$ of the installed wind power capacity. The pattern follows this explanation: for high penetration the mean displaced capacity decreases with a low scatter to a value near the minimum load factor; for low penetration the mean displaced capacity is close to the average load factor, while the scatter is very large.* The average production (load factor) is $22 \%$ (see Table II), but the

* This does not explain the increase in relative displaced capacity for the first few points of the baseline plot. It is probably due to the discrete power plant size. The unused fossil fuel capacity for $0.8 \%$ newly installed capacity is for the Selection series at $550 \mathrm{MW}$, a size where one or two typical coal-fired power stations are being replaced. In most cases it replaces only one while reducing the load factor of the other. That other one is then still counted as needed. 


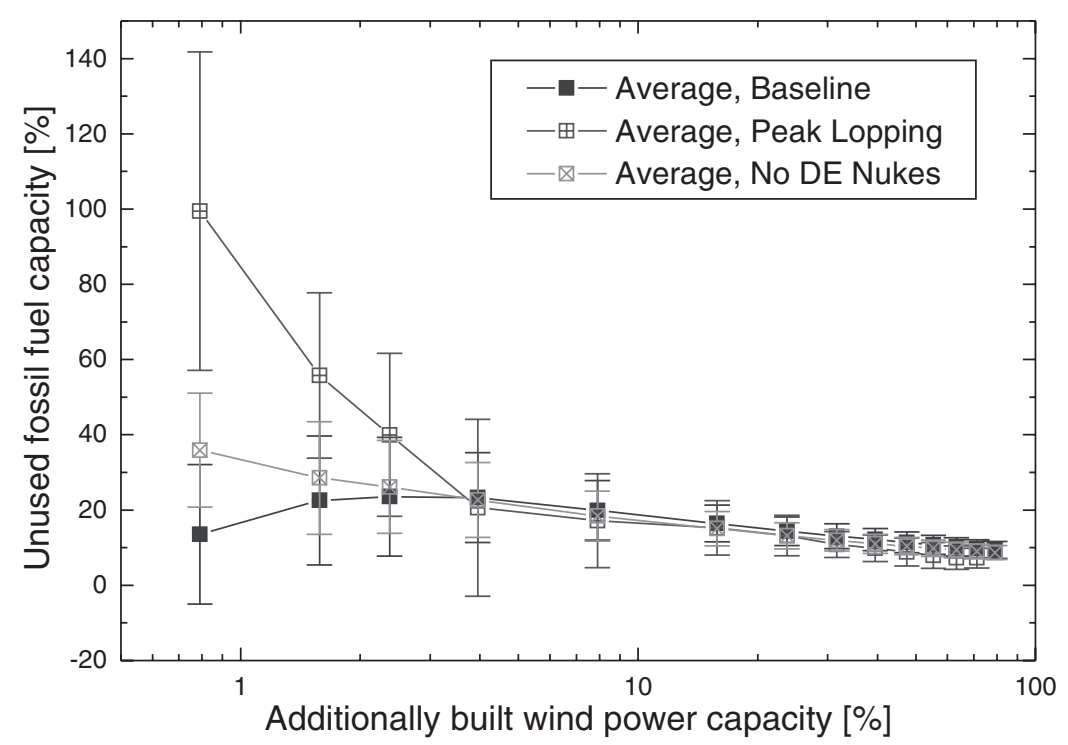

Figure 4. Variation of the unused fossil fuel capacity with increased penetration. The x-axis is logarithmic to show the small penetrations better. The y-axis is scaled in installed wind power capacity as \% of installed previous power capacity

average production of the European 'average' series during the 7 week period of the highest load is about 30\%, which is also the value reached for zero penetration when extrapolating the linear part in the $\log -\log$ plot above. Note that for low penetration the use of pump storage plant for peak lopping can increase the capacity credit of wind energy for small penetrations to nearly $100 \%$ of the installed capacity.

\section{The Long Term: Reanalysis}

In the course of the last section the importance of the load factor during the period of the highest load for a capacity credit assessment has been stressed. The lack of detailed data for more than 1 year in this study can be overcome with the use of reanalysis data, which are available for 34 years. Therefore an assertion can be made regarding the long-term effects on the previous analysis.

Figure 5 shows the mean power production for the 7 week period of the highest load. Our reference year 1991 is actually one of the worst-producing winter periods in the whole period. This means that 1991 was one of the worst years to use for a capacity assessment of wind energy. In other words, the results presented in the previous section should be treated as a worst-case scenario.

\section{Summary/Conclusions}

The assessment of the capacity credit of wind energy by means of a chronological scheduling model is very sensitive to single events. The scheduling model can be used nonetheless to assess the fossil fuel savings due to wind energy. It also can help in estimating the benefits of distributed generation or various forecasting options. Using data from 60 meteorological stations all over Europe, the resulting wind generation time series was fed into the National Grid Model, a scheduling model run as a one-node model with a mainly thermal and nuclear system of Europe (essentially the EU-15). Wind energy can contribute more than $20 \%$ of the European electricity demand, taking a loss of $10 \%$ of the generated wind energy into account, part of which could be saved in the hydro reservoirs not modelled here. Under the assumptions of the scheduling model, this leads 


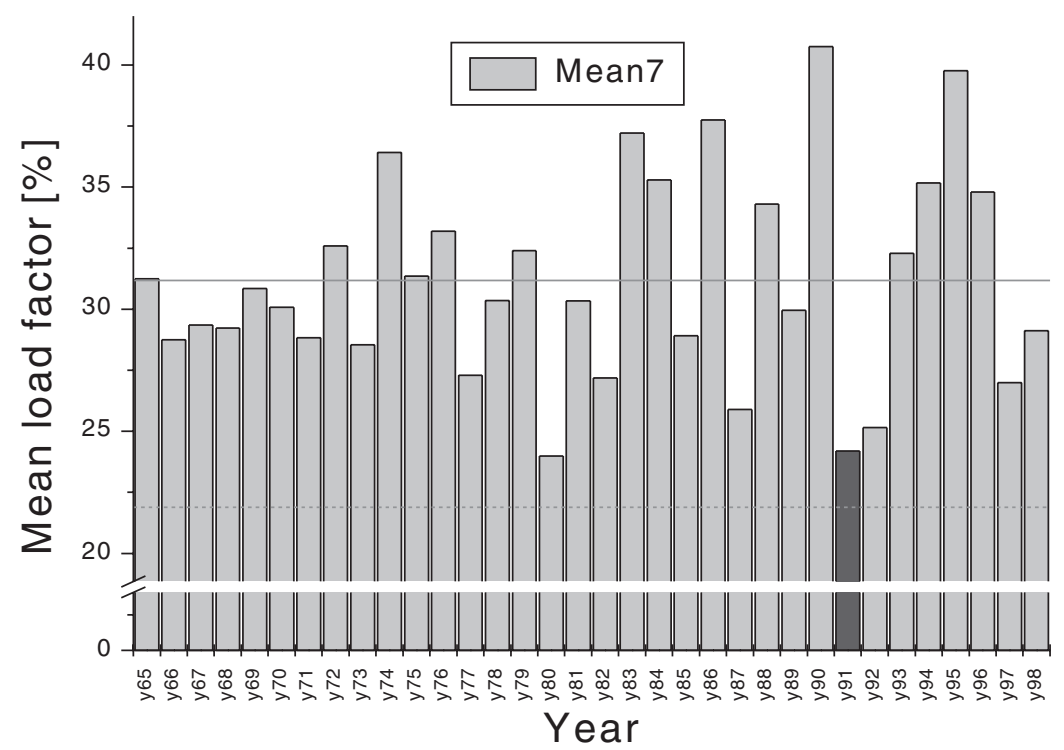

Figure 5. Mean load factor for the 'average' series, averaged over the 7 week period of the highest load. The full line shows the average over all columns, while the broken line corresponds to the overall mean power production

to savings of $60 \%$ of the fossil fuel cost, worth about $7 \mathrm{G} €$, corresponding to $22 € / \mathrm{MWh}$ as the value of wind power in pure fuel saver mode. The installed wind power capacity replaces at this stage fossil-fuelled power plants worth somewhat more than $10 \%$ of the installed wind power capacity. The use of pump storage can increase the capacity credit for small penetrations to up to $100 \%$. Using a 34 year time series derived from reanalysis data, this could be shown to be a worst-case scenario, since the analysed year was one of the worst in terms of average load factors during the high-load period.

\section{Acknowledgements}

Most of the research was carried out under a Marie Curie Fellowship grant (JOR3-CT97-5004). EDF (France) is thanked for donating a load time series to the project. Special thanks are due to Hannele Holttinen for valuable comments.

\section{References}

1. Giebel G. On the benefits of distributed generation of wind energy in Europe. PhD Thesis, Carl von Ossietzky Universität Oldenburg, 2001.

2. Giebel G. Wind energy has a capacity credit - a catalogue of 50+ supporting studies. WindEng eJournal 2004. [Online]. Available: ejournal.windeng.net/3 (Accessed 13 August 2006).

3. Milligan MR. Variance estimates of wind plant capacity credit. NREL/TP-440-21311, National Renewable Energy Laboratory, Golden, CO, 1996.

4. Bossanyi EA. Use of a grid simulation model for longer-term analysis of wind energy integration. Wind Engineering 1983; 7: 223-246.

5. Bossanyi EA, Halliday JA. Recent developments and results of the Reading/RAL grid simulation model. In Proceedings of 5th BWEA Conference, Reading. Musgrove PJ (ed.) Cambridge University Press: Cambridge, 1983; 62-74.

6. Drezga I, Rahman S. Input variable selection for ANN-based short-term load forecasting. IEEE Transactions on Power Systems 1998; 13: 1238-1244.

7. Daneshdoost M, Lotfalian M, Bumroongit G, Ngoy JP. Neural network with fuzzy set-based classification for shortterm load forecasting. IEEE Transactions on Power Systems 1998; 13: 1386-1391. 
8. Khotanzad A, Afkhami-Rohani R, Maratukulam D. ANNSTLF-artificial neural network short-term load forecaster, generation three. IEEE Transactions on Power Systems 1998; 13: 1413-1422.

9. Giebel G, Kariniotakis G, Brownsword R. The state-of-the-art in short-term forecasting of wind power-a literature overview. Position paper for the Anemos project. [Online]. 2003. Available: anemos.cma.fr. (Accessed 13 August 2006)

10. Landberg L. The availability and variability of the European wind resource. International Journal of Solar Energy 1997; 18: 313-320.

11. Landberg L. Short-term prediction of local wind conditions. Ris $\phi-R-702(E N)$, Ris $\emptyset$ National Laboratory, Roskilde, 1994.

12. Giebel G. Effects of distributing wind energy generation over Europe. Proceedings of European Wind Energy Conference, Nice, 1999; 417-420.

13. Giebel G. Equalizing effects of the wind energy production in northern Europe determined from reanalysis data. Ris $\phi$ $R-1182(E N)$, Ris $\emptyset$ National Laboratory, Roskilde, 2000.

14. IEA Electricity Information 96. OECD Publications: Paris, 1996.

15. Knox R. Power plant performance. Nuclear Engineering International 1998; 43: 36-39.

16. Kalney E, Kanamitsu M, Kistler R, Collins W, Deaven D, Gandin L, et al. The NCEP/NCAR 40-year reanalysis project. Bulletin of the American Meteorological Society 1996; 77: 437-471 (see also http://wesley.wwb.noaa.gov/ reanalysis.html).

17. Focken U, Lange M, Mönnich K, Waldl H-P, Beyer HG, Luig A. Short-term prediction of the aggregated power output of wind farms - a statistical analysis of the reduction of the prediction error by spatial smoothing effects. Journal of Wind Engineering and Industrial Aerodynamics 2002; 90: 231-246. 